\title{
MEASUREMENTS OF FLOWS IN THE DIII-D DIVERTOR BY MACH PROBES
}

RECEIVE

JUL 161998

OSTI

\author{
by
J.A. BOEDO, R. LEHMER, R.A. MOYER, J.G. WATKINS,
PORTER, T.E. EVANS, A.W. LEONARD, and M.J. SCHAFFER \\ J.A. BOEDO, R. LEHMER, R.A. MOYER, J.G. WATKINS,
PORTER, T.E. EVANS, A.W. LEONARD, and M.J. SCHAFFER \\ J.A. BOEDO, R. LEHMER, R.A. MOYER, J.G. WATKINS,
G.D. PORTER, T.E. EVANS, A.W. LEONARD, and M.J. SCHAFFER
}

DISTRIBUTON OF THIS DOCUMENT IS UNE WSTE.

JUNE 1998 


\section{DISCLAIMER}

This report was prepared as an account of work sponsored by an agency of the United States Government. Neither the United States Government nor any agency thereof, nor any of their employees, make any warranty, express or implied, or assumes any legal liability or responsibility for the accuracy, completeness, or usefulness of any information, apparatus, product, or process disclosed, or represents that its use would not infringe privately owned rights. Reference herein to any specific commercial product, process, or service by trade name, trademark, manufacturer, or otherwise does not necessarily constitute or imply its endorsement, recommendation, or favoring by the United States Government or any agency thereof. The views and opinions of authors expressed herein do not necessarily state or reflect those of the United States Government or any agency thereof. 


\section{DISCLAIMER}

Portions of this document may be illegible electronic image products. Images are produced from the best available original document. 


\title{
MEASUREMENTS OF FLOWS IN THE DIII-D DIVERTOR BY MACH PROBES
}

\author{
by \\ J.A. BOEDO, † R. LEHMER, † R.A. MOYER, † J.G. WATKINS, \\ G.D. PORTER,, T.E. EVANS, A.W. LEONARD, and M.J. SCHAFFER
}

This is a preprint of a paper to be presented at the 13th International Conference on Plasma Surface Interactions on Controlled Fusion Devices, May 18-23, 1998, San Diego, California and to be published in Journal of Nuclear Materials.

\author{
†University of California, San Diego \\ ¥Sandia National Laboratories, Albuquerque \\ OLawrence Livermore National Laboratory
}

\begin{abstract}
Work supported by
the U.S. Department of Energy

under Contracts DE-AC03-89ER51114, DE-AC04-94-AL85000, W-7405-ENG-48, and Grant DE-FG03-95ER54294
\end{abstract}

\author{
GA PROJECT 3466 \\ JUNE 1998
}




\begin{abstract}
First measurements of Mach number of background plasma in the DIII-D divertor are presented in conjunction with temperature $T_{e}$ and density $n_{e}$ using a fast scanning probe array. To validate the probe measurements, we compared our $T_{e}, n_{e}$ and $J_{\text {sat }}$ data to Thomson scattering data and find good overall agreement in attached discharges and some discrepancy for $T_{e}$ and $n_{e}$ in detached discharges. The discrepancy is mostly due to the effect of large fluctuations present during detached plasmas on the probe characteristic; the particle flux is accurately measured in every case.

A composite 2-D map of measured flows is presented for an ELMing $\mathrm{H}$-mode discharge and we focus on some of the details. We have also documented the temperature, density and Mach number in the private flux region of the divertor and the vicinity of the $\mathrm{X}$-point, which are important transition regions that have been little studied or modeled. Background parallel plasma flows and electric fields in the divertor region show a complex structure.
\end{abstract}





\section{INTRODUCTION}

Divertors are a critical component of existing, and planned, magnetic confinement fusion experiments. The role of the divertor is to assure heat and particle exhaust while allowing impurity entrainment. Impurities, mostly carbon, are present in tokamak plasmas as they are released from plasma facing components through physical and chemical sputtering [1]; these processes also damage the divertor components. There is thus a need to understand and study divertor physics and in particular any process, such as plasma flow, that can transport heat and particles to the divertor components, causing structural damage. Plasma flows can also affect particle and power fluxes $[2,3]$ to the target plates and pumping apparatus and therefore are critical to the design of divertors.

Indications that flows in the divertor can exhibit complex behavior have been obtained from 2-D modeling [4,5] but insofar been mostly unconfirmed. An important phenomenon which affects flow physics is that of flow reversal. Flow reversal has been predicted analytically [6] and it is expected when the ionization source arising from neutral or impurity recycling in the divertor region is so large that the target plate, limited by the ion saturation current, can not absorb all the particles. Reversed flow is expected to first appear near the $40 \mathrm{eV}$ electron temperature contour, where the ratio of the rate coefficient for electron impact ionization to the square root of the temperature $\langle\sigma v\rangle / \mathrm{T}_{\mathrm{e}}^{1 / 2}$, is maximum and therefore the particle source becomes large. Simulations by UEDGE [4], a 2-D fluid plasma and neutral code predict flow reversal in the DIII-D divertor, approximately in regions which follow the $40 \mathrm{eV}$ contour.

In order to reduce the heat and particle fluxes to the divertor target plates, a radiative divertor regime has been proposed in which the energy and momentum of the plasma are dissipated into a large amount of neutral gas introduced in the divertor region, cooling the plasma by collisional and atomic processes so that the plasma is then detached from the target plates. These radiative divertor regimes have been the subject of extensive studies [7] and it has been recently proposed that the energy transport over large regions of the divertor must be dominated by convection [8] instead of conduction. It is therefore important to understand the role of the plasma conditions and geometry on determining the region of convection-dominated plasma in order to properly control the heat and particle fluxes to the target plates and hence, divertor performance.

Some efforts have been made to characterize plasma and impurity flows in the divertor region with spectroscopy in ASDEX-Upgrade [9] and DIII-D [10] or with probes as in Alcator C-Mod [11], TdeV [12], and ASDEX-Upgrade [13] yet results are still emerging within a growing body $[14,15]$ of well documented divertor physics. 
We present in this paper first results of parallel background plasma flow obtained with scanning Mach probes in the divertor region of DIII-D. The measurements are intrinsically local and obtained with high spatial resolution $(2-3 \mathrm{~mm}$ ). The geometry of the divertor (open) and the location of the probe at the divertor target plate allow access to divertor regions not previously studied in other devices. 


\section{EXPERIMENTAL SET-UP}

The experiments have been performed on the DIII-D tokamak in discharges with plasma current $\mathrm{I}_{\mathrm{p}}=1.4 \mathrm{MA}$, toroidal field $\mathrm{B}_{\mathrm{t}}=2 \mathrm{~T}$, flat-top duration of $5 \mathrm{~s}$ and chord-averaged density of $0.5-1.0 \times 10^{20} \mathrm{~m}^{-3}$. The discharges are heated primarily by neutral beam injection at power levels of $4.5 \mathrm{MW}$. If a strong gas puff is introduced during the discharge, the divertor plasma temperature drops and the density increases as it detaches from the target plate.

A fast scanning probe array [16] is introduced vertically into the divertor plasma as shown in Fig. 1 with two of the tips configured as a Mach probe and two as a double probe. The magnetic configuration is the product of magnetic reconstruction performed by the code EFIT [17]. The Mach probe consists of two tips, aligned with the magnetic field, collecting saturation current. We utilize well known models by Chung and Hutchinson $[18,19]$ to interpret the measured Mach probe currents as plasma Mach number. The plasma flow velocity is obtained by multiplying the local Mach number by the local sound speed $c_{s}=\left(\gamma Z k T_{e} / m_{i}\right)^{1 / 2}$ where $\mathrm{k}$ is the Boltzmann constant, $T_{e}$ and $T_{i}$ are the electron and ion temperature, $\gamma$ is the adiabatic constant and $m_{i}$ is the ion mass. The voltage applied to the Mach tips is swept at $1 \mathrm{kHz}$ to prevent sustained arcing, thus damage, to the tips when overheating occurs.

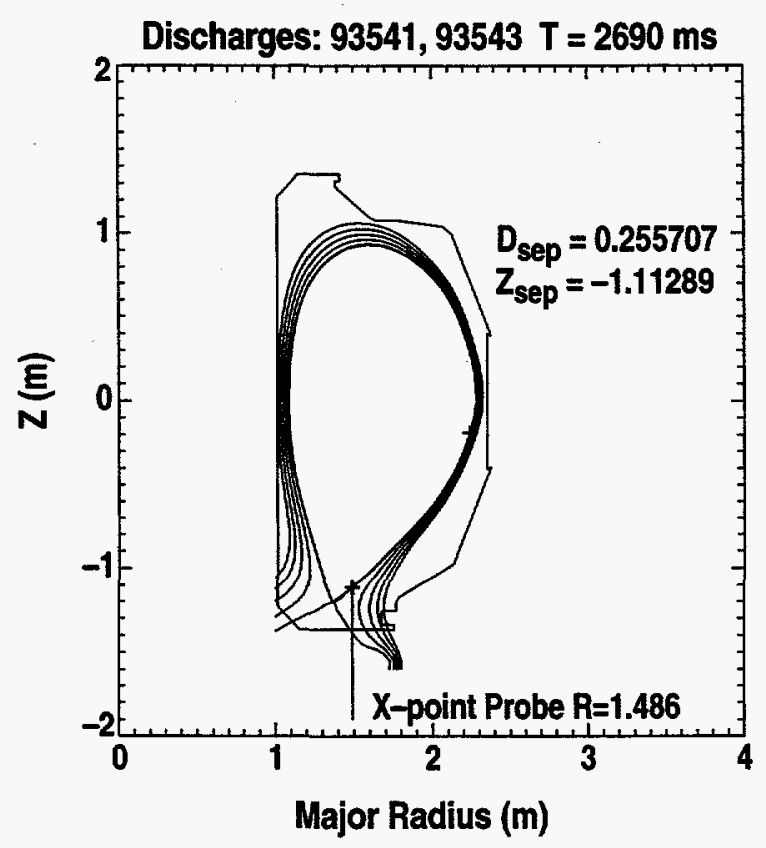

Fig. 1. The position of the scanning probe is superimposed on the reconstructed magnetic geometry for H-mode discharges. The probe moves along the outer SOL. 
There are two sources of concern regarding the quality of the Mach measurement, the flow velocity to be derived from it and the probe data in general, namely: 1) the proximity of the probe to the divertor floor and 2) observed discrepancies between probe and Thomson scattering data during highly radiative discharges. We discuss the first concern here and the second in the "Results" section.

In a first approximation, the probe measurements can be disturbed if the connection length between the measuring tip and the divertor target plate is of the order of the probe collection length $\mathrm{L}_{\mathrm{p}}$ or smaller. The plasma contained in the collection tube of the tip, filled by diffusion from surrounding plasma, is depleted by plasma flowing towards the divertor plate at a higher rate than it can be filled to reflect the properties of the main, unperturbed plasma. We estimate this critical distance [20], $L_{p}$, in terms of the probe area $d^{2}$, the local sound speed $c_{s}$, and diffusion coefficient $D_{\perp}$, to be $\mathrm{L}_{\mathrm{p}}=\mathrm{d}^{2} \mathrm{c}_{S} / 4 \mathrm{D}_{\perp}$ or $10-15 \mathrm{~cm}$ for DIII-D parameters $\left(\mathrm{d}^{2} \sim 1 \mathrm{~mm}^{2}\right.$, $D_{\perp} \sim 0.3 \mathrm{~m}^{2} / \mathrm{s}, \mathrm{c}_{\mathrm{s}} \sim 7 \times 10^{6} \mathrm{~cm} / \mathrm{s}$ ), which corresponds to a height of the probe from the floor of < $1 \mathrm{~cm}$. We observe experimentally that the measurements are perturbed for an elevation of $<2 \mathrm{~cm}$, which suggests that the diffusion coefficient used for the above estimate is too large or, equivalently, that the probe body plays a bigger role than expected and prevents the collection tube from filling up faster. 


\section{RESULTS AND DISCUSSION}

We present in this paper results that address two issues: 1) the validity of the Mach measurement for a variety of conditions by comparing probe data and Thomson scattering data and 2) initial measurements of Mach number, flow velocity, saturation current and plasma potential in the divertor region, results presented in a coarse 2-D map from a multi-discharge divertor sweep. All experiments were performed in discharges such as those described in Section 2.

To validate the probe data, we obtained probe measurements for attached, recombining and detached divertor plasmas and compared them to Thomson scattering measurements taken at the same time. The geometry of the experiment is shown in Fig. 1.

The $T_{e}$ and $n_{e}$ measurements from the probe compare to Thomson's within $20 \%$ for attached plasmas as shown in Fig. 2-a but differ for detached [Fig. 2(c)] or recombining [Fig. 2(b)] plasmas, where the probe measurements of $T_{e}$ feature a variable degree of agreement with Thomson $\mathrm{T}_{\mathrm{e}}$ and can be higher by factors of up to 2-3 [21], whereas the probe measurements of $n_{e}$ are lower by $30 \%$. The discrepancy on the $T_{e}$ measurements can be traced to high levels of fluctuations present in highly radiating divertors, which distort the measured I-V characteristic and tend to flatten the fit, therefore increasing the apparent temperature. This conclusion has been reached for floor probe data under similar conditions [22] in DIII-D. An important fact is that the probe measurement of $\mathrm{J}_{\text {sat }}$ agrees with that inferred from Thomson data as seen in Fig. 2(a,b) and Fig. 2(c), within $20 \%$ in all cases. The comparison of measurements suggests that the calculation of the sound speed in recombining or detached discharges, if inferred from probe data, can be overstated by $\sqrt{\mathrm{T}_{\mathrm{e}}^{\text {Probe }} / \mathrm{T}_{\mathrm{e}}^{\text {Thomson }}}$ which can be as high as $1.4-1.7$. The result that $\mathrm{J}_{\text {sat }}$ is properly measured at all times assures us that the Mach number, dependent on the ratio of saturation currents from two pins, is always correct.

We have obtained a coarse 2-D map of various divertor plasma parameters, including Mach number and flow velocity, during experiments where the divertor $\mathrm{X}$-point is swept from smaller to larger major radius, in a shot to shot basis. The X-point sweep enables the scanning probe to investigate various regions of the divertor. We show the results of such a survey in Fig. 3 for attached divertor plasmas in a slowly ELMing $(25 \mathrm{~Hz}) \mathrm{H}$-mode discharge as described in Section 2. The Mach number [Fig. 3(b)] and flow velocity [Fig. 3(c)] plots show that the flow velocity increases towards the target plate everywhere in the lower divertor as expected from sheath acceleration considerations but that flow stagnation is already apparent above the $\mathrm{X}$-point in the outer divertor leg. We also observe fine flow structures at the outer separatrix which 

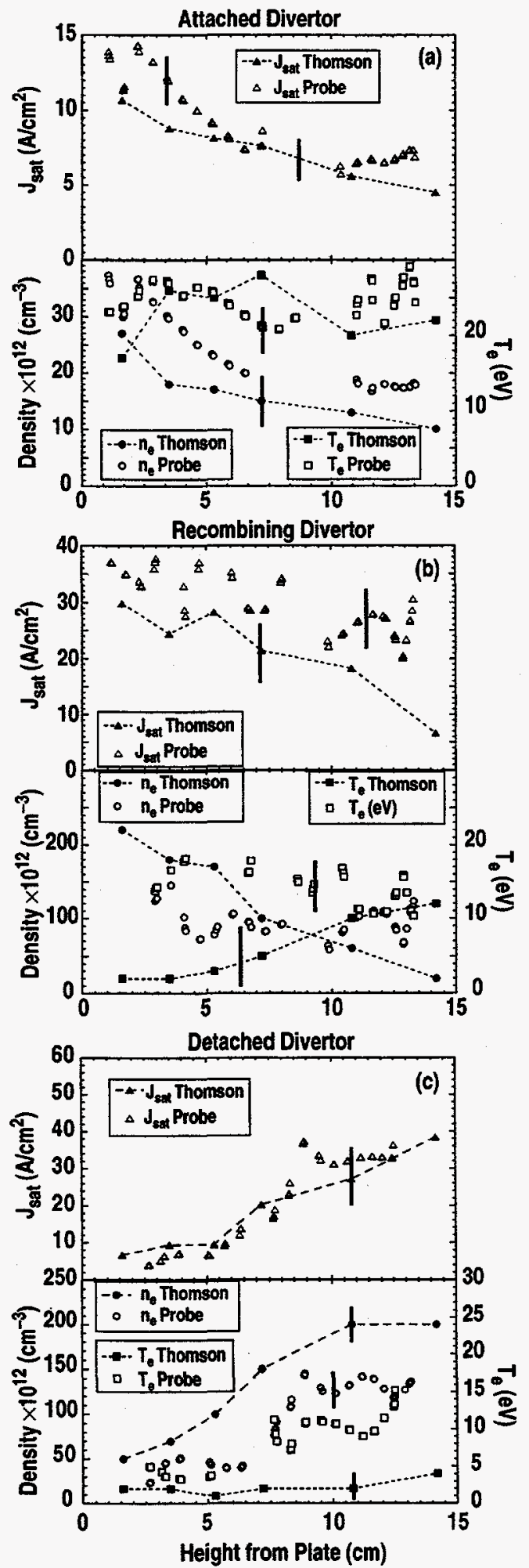

Fig. 2. Comparison of $J_{\text {sat }}$ (upper panels), $T_{e}$ and $n_{e}$ (lower panels) measured by the probe (open symbols) and measured by Thomson scattering (filled symbols, dashed line) for (a) attached divertor plasma, (b) recombining divertor plasma and (c) detached divertor plasma. 


\section{Slowly ELMing H-Mode}
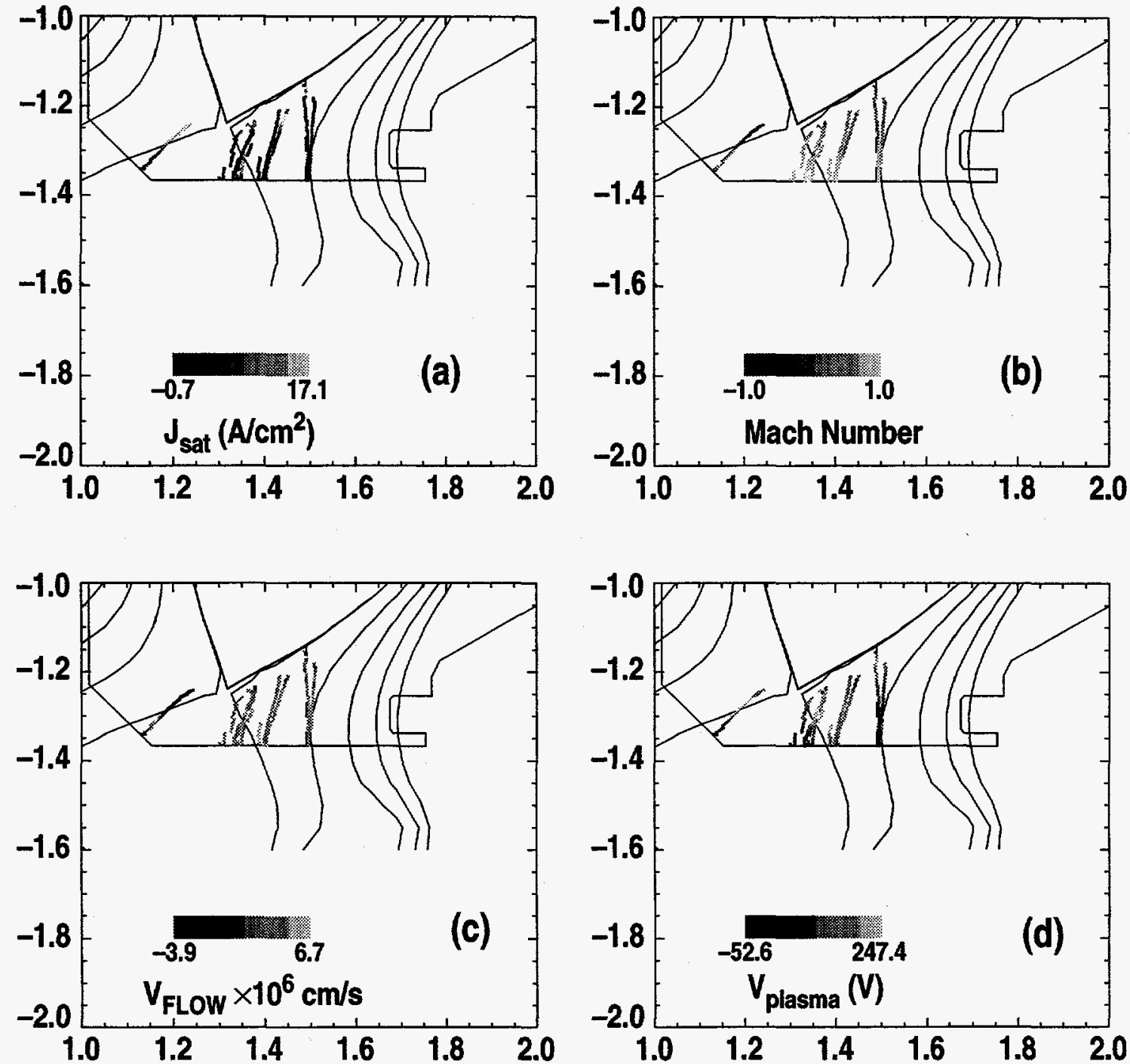

Fig. 3. 2-D plot built over the slowly ELMing phase of several discharges of (a) Ion saturation current, (b) Mach number, (c) Flow velocity and (d) Plasma potential.

correspond to flow reversal or slowdown. The slowdown of flow near the X-point and the outer separatrix should be related to pressure zones determined by ionization sources [7]. The ionization sources are due to neutral gas and carbon sources at the surfaces facing the plasma. The data shows that the plasma potential [Fig. 3(d)] features a large gradient when crossing the separatrix. These gradients $(50-200 \mathrm{~V} / \mathrm{cm})$ will produce strong poloidal $\mathrm{E} \times \mathrm{B}$ flows of the order of $0.2-110^{6} \mathrm{~cm} / \mathrm{s}$ which are expected to affect the parallel flow patterns and produce considerable velocity shear that can stabilize turbulence in the divertor region. The saturation current [Fig. 3(a)] in the divertor features sharp gradients at the inner and outer separatrix. 
The fairly complex structure of plasma parameters in the divertor region has important implications for plasma and divertor performance. The flow of plasma determines particle and energy transport in the divertor by means of convection, thus affecting the divertor basic functions of particle and energy exhaust. The velocity of the background plasma is involved in the balance of forces acting on impurities, such as carbon, that contaminate the core plasma and reduce performance, thus the impurity transport can be greatly determined by the background plasma convection as well. 


\section{CONCLUSIONS}

Double probe measurements of electron temperature and density in the divertor region agree well with Thomson scattering measurements for attached plasmas and tend to differ for detached and recombining plasmas, yet the particle flux agrees well within errors. A 2-D survey of the divertor, performed by a fast scanning probe array, determined that background plasma flows in the divertor region have a complex structure. The plasma flow velocity increases towards the divertor target plate as expected from free fall acceleration produced by the pre-sheath and it shows stagnation far away from the plate and the LCFS. The flow structure has important implications for particle and energy exhaust and thus will be the subject of more detailed studies in DIII-D. 



\section{REFERENCES}

[1] T.E. Evans, D.F. Finkentahl, Y. Loh, et al., General Atomics Report GA-A22693 (1998), Submitted to Plasma Phys. and Contr. Fusion.

[2] M.J. Schaffer, D.G. Whyte, N. Brooks, et al., Nucl. Fusion 35 No. 8 (1995).

[3] M.R. Wade, J.T. Hogan, R. Maingi, et al., Submitted to Nucl. Fusion (1998).

[4] T. Ronglien, J. Milosevitch, M. Rensik and G. Porter, J. Nucl. Mater., 196-198, (1992) 347351.

[5] G.D. Porter and the DIII-D Team, Proc. 23rd European Conf. on Contr. Fusion and Plasma Physics, Kiev, Russia, Vol. 20C, Part II, (1996) 699.

[6] P.I.H. Cooke, A.K. Prinja, Nucl. Fusion 27 No. 7 (1987).

[7] M.A. Mahdavi, S.L. Allen, N.H. Brooks, et al., Proc. 16th Int. Conf. on Fusion Energy, Montreal, IAEA-CN-64/A4-3 (1996) 397.

[8] A.W. Leonard, M.A. Mahdavi, S.L. Allen, et al., Phys. Rev. Lett. 78, No. 25, (1997) 4769.

[9] J. Gafert, et al., Plasma Phys. Contrl. Fusion 39, (1997) 1981.

[10] R.C. Isler et al., "Normalized and Reversed Impurities Flows in the DIII-D Divertor," to be published in Phys. Rev. Lett.

[11] B. LaBombard, J.A. Goetz, I. Hutchinson, et al., J. Nucl. Mater., 241-243 (1997) 149-166.

[12] B.L. Stansfield et al., J. Nucl. Mater. 220-222 (1995) 1121.

[13] C.S. Pitcher, H.S. Bosch, et al., Proc. 20th European Conf. on Contr. Fusion and Plasma Physics Vol. I, (1993) 1-73.

[14] M.E. Fenstermacher, S.L. Allen, N.H. Brooks, et al., Phys. Plasmas 4 (5), (1997), 1761.

[15] M.E. Fenstermacher, R.D. Wood, S.L. Allen, et al., J. Nucl. Mater. 241-243 (1997) 666671.

[16] J.G. Watkins, et al. Rev. Sci. Instrum. 68 (1), 1997.

[17] L.L. Lao, T.H. Jensen, et al., Nucl. Fusion 31 (1985) 1111.

[18] K.S. Chung, I. Hutchinson, et al, Phys. Rev. A 38, No 9 (1988).

[19] K.S. Chung, I. Hutchinson, et al, Phys. Fluids 3, No. 11, (1991).

[20] P.C. Stangeby et al., Nucl. Fusion 30, No. 7, (1990) 1225.

[21] R.A. Moyer, J. Cuthbertson, et al., J. Nucl. Mater. 241-243 (1997) 633-638.

[22] J.G. Watkins et al., these proceedings. 



\section{ACKNOWLEDGMENTS}

Work supported by U.S. Department of Energy under Grant No. DE-FG03-95ER54294, and Contracts DE-AC03-89ER51114, DE-AC04-94AL85000, and W-7405-ENG-48. 